(c) American Dairy Science Association, 2005.

\title{
Optimization of Individual Prestimulation in Dairy Cows
}

\author{
D. Weiss and R. M. Bruckmaier \\ Physiology Weihenstephan, Technical University Munich, \\ D-85350 Freising, Germany
}

\section{ABSTRACT}

The application of prestimulation results in enhanced milking performance compared with milking without prestimulation. In the present study oxytocin (OT) release and milking characteristics were investigated in 43 dairy cows after the application of various prestimulation routines by vibration stimulation lasting between 0 and $90 \mathrm{~s}$. Additionally, different maximum pulsation vacuum settings during vibration stimulation were investigated. The actual degree of udder fill was calculated as a percentage of the estimated storage capacity. The amplitude of OT release, total milk yield, and stripping milk yield did not differ between prestimulation routines. Increased maximum pulsation vacuum during vibration stimulation resulted in milk flow during prestimulation, but did not negatively influence milking characteristics. The lag time from the start of teat stimulation until the start of milk ejection was negatively correlated with the degree of udder fill. This relationship was the reason for variations in optimal duration of prestimulation. The optimal duration of prestimulation to receive immediate and continuous milk flow at the start of milking was $90 \mathrm{~s}$ in udders containing small amounts of milk, whereas the optimal duration was only $20 \mathrm{~s}$ in well-filled udders. A short prestimulation enhances milking stall capacity when milking full udders, and a prolonged prestimulation reduces the total vacuum load on the teat when milking udders that are not full.

(Key words: prestimulation, oxytocin, milk flow, cattle)

\begin{abstract}
Abbreviation key: AFR = average flow rate; $\mathbf{M P V}=$ maximum pulsation vacuum during vibration stimulation; $\mathbf{P F R}=$ peak flow rate; $\mathbf{O T}=$ oxytocin .
\end{abstract}

\section{INTRODUCTION}

The release of oxytocin (OT) from the pituitary is essential for the ejection of alveolar milk (Lefcourt and

Received April 8, 2004

Accepted September 17, 2004.

Corresponding author: Rupert M. Bruckmaier; e-mail: bruckmaier @wzw.tum.de.
Akers, 1983; Bruckmaier and Blum, 1998). Oxytocin is released in response to tactile teat stimulation. The stimulation by the liner during milking pulsation has been as effective as manual prestimulation in inducing OT release in dairy cows (Bruckmaier and Blum, 1996). Even cluster attachment without liner pulsation caused sufficient OT release to induce the alveolar milk ejection (Weiss et al., 2003). However, OT concentrations need to be elevated throughout milking to ensure complete udder evacuation (Bruckmaier et al., 1994).

Before the onset of alveolar milk ejection, only the milk stored in the cisternal cavities is available for machine milking (Bruckmaier and Blum, 1996, 1998). The application of a fixed prestimulation of 30 to $60 \mathrm{~s}$ before milking has been recommended to ensure immediate and continuous milk flow after the start of milking (Mayer et al., 1985; Rasmussen et al., 1990, 1992). However, recent investigations demonstrated the importance of the udder fill on the course of milk ejection (Bruckmaier and Hilger, 2001; Dzidic et al., 2004). Therefore, prestimulation time according to the degree of udder fill in individual cows may improve the milking performance. To minimize the labor requirements of prestimulation, the application of a vibration pulsation may be a favorable option (Karch et al., 1988).

In the present study, we tested the hypothesis that the optimal duration of prestimulation to minimize the machine milking time is determined by the degree of udder fill. Oxytocin concentrations during the course of prestimulation and milking were determined to evaluate effects of prestimulation on the release of OT. Additionally, the effect of vibration stimulation settings on OT release and milk flow characteristics was evaluated.

\section{MATERIALS AND METHODS}

\section{Animals and Husbandry}

Forty-three experimental cows (Brown Swiss $\times$ German Braunvieh) were milked twice daily in a $2 \times 2$ tandem milking parlor. Milking started at 0500 and $1600 \mathrm{~h}$. The resulting milking interval was $13 \mathrm{~h}$ during the night and $11 \mathrm{~h}$ during daytime. Most cows were in the first to tenth month of lactation, although one cow was in the 23rd month of lactation due to unsuccessful 
breeding. Parity ranged from 1 to 6 lactations. All experimental cows were free of clinical mastitis. The diet consisted of corn and grass silage, hay ad libitum, and concentrate according to the animals' individual production levels provided by automatic feeders. Cows were collected immediately before milking and received no concentrate in the parlor. Milking was performed at a vacuum of $40 \mathrm{kPa}$, a pulsation rate of 60 cycles/min and a pulsation ratio of $60 \%$. Machine stripping was applied manually after milk flow dropped below a threshold of $0.3 \mathrm{~kg} / \mathrm{min}$. A conventional milking cluster (No. 7021-2620-310, WestfaliaSurge GmbH, 59299 Oelde, Germany) equipped with liner (No. 7021-2725230) was used during the experiments.

\section{Experimental Design}

Experiment 1. Oxytocin concentrations during milkings were recorded with 2 milkings each treatment (a.m. and p.m.) in 6 cows. Cows were catheterized in one jugular vein for blood sampling on the day before the start of the first experimental milking. Immediately before the start of milking, vibration stimulation at 300 cycles/min was applied (Karch et al., 1988; Stimopuls $\mathrm{P}$, WestfaliaSurge $\mathrm{GmbH}$ ). The pressure difference to open and close the liner was about $9 \mathrm{kPa}$. However, because the pulsation frequency of $300 \mathrm{cycles} / \mathrm{min}$ was very high during vibration pulsation, the liner opened slightly at a maximum pulsation vacuum (MPV) of 30 $\mathrm{kPa}$, but not at an MPV of 17 and $24 \mathrm{kPa}$, because the inertia of the liner was higher than the applied vacuum forces (Figure 1). To avoid additional stimulatory effects, the teats were not cleaned, fore-stripped, or touched before teat cups were attached. Thus, the duration of the prestimulation by vibration stimulation was exactly the time between the first contact to the teats and the start of milking pulsation. Treatments performed were milking without prestimulation, prestimulation for $60 \mathrm{~s}$ at an MPV of 17 or $30 \mathrm{kPa}$, and prestimulation for $90 \mathrm{~s}$ at an MPV of $24 \mathrm{kPa}$.

Blood samples were taken from 1 min before the start of stimulation. From the start of stimulation until 1.5 min after the start of stimulation the sampling interval was $15 \mathrm{~s}$. Thereafter, blood samples were taken at 1min intervals until cluster removal at the end of milking. Blood samples were treated with EDTA to prevent coagulation and centrifuged at $1500 \times \mathrm{g}$ for $15 \mathrm{~min}$ within 20 min of collection. Plasma was stored at $-20^{\circ} \mathrm{C}$ until used for radioimmunological determination of OT concentration according to Schams (1983).

Milk flow profiles were registered by strain gauge recorder jars and processed using a program package as previously described (Worstorff and Fischer, 1996). The obtained milk flow profiles were visually checked for plausibility and were rejected in case of failings, for example, cluster fall off or in case of additionally applied cleaning due to extremely dirty teats. Milking characteristics were evaluated according to Bruckmaier et al. (1995).

Experiment 2. Milk flow profiles were recorded in all 43 experimental cows. The duration of vibration stimulation was varied in 5 steps: $0,20,40,60$, and 90 $\mathrm{s}$ at an MPV of $24 \mathrm{kPa}$. Each treatment block was applied in a sequence of 4 milkings and the entire block was repeated once, in randomized order. Additionally, 2 milkings with the respective settings were performed before experimental recordings.

Actual milk yield as a percentage of maximum storage capacity was estimated to describe the degree of udder fill in classes of 0 to 20,20 to 40,40 to 60,60 to 80 , and 80 to $100 \%$, respectively, as previously described (Bruckmaier and Hilger, 2001; Weiss et al., 2002). Maximum storage capacity of the mammary gland was estimated as half of the maximum daily milk yield in mo 2 of the respective lactation. The mean udder fill of individual cows throughout the experimental period was calculated separately for morning and evening milkings. Therefore, an average udder-fill rate was obtained for morning and evening milkings of the individual animal. The lag time between the start of stimulation and the start of the alveolar milk ejection was visible as a prolonged period of milking pulsation in the absence of milk flow or as a transient reduction of milk flow due to the limited amount of cisternal milk within the first minute of milking. The following increase of the milk flow indicated the start of milk ejection (Bruckmaier and Blum, 1996; Bruckmaier and Hilger, 2001).

Experiment 3. In a separate experiment, 2 treatments with duration of prestimulation of $60 \mathrm{~s}$ and MPV adjusted to 17 or to $30 \mathrm{kPa}$ were performed in all 43 experimental cows. These treatments were applied in a sequence of 4 milkings. Additionally 2 milkings with the respective settings were performed before experimental recordings.

\section{Statistical Analyses}

Results are presented as means \pm SEM. For statistical analyses, the SAS program package release 8.01 (SAS Institute, 1999) was used. Treatment effects were tested for significance $(P<0.05)$ using the MIXED procedure in SAS.

The model used to analyze experiment 1 was:

$$
\mathrm{Y}_{\mathrm{ijk}}=\mu+\mathrm{T}_{\mathrm{i}}+\mathrm{S}_{\mathrm{j}}+\mathrm{T}_{\mathrm{i}} \times \mathrm{S}_{\mathrm{j}}+\operatorname{Cow}_{\mathrm{k}}\left(\mathrm{T}_{\mathrm{i}}\right)+\varepsilon_{\mathrm{ijk}}
$$



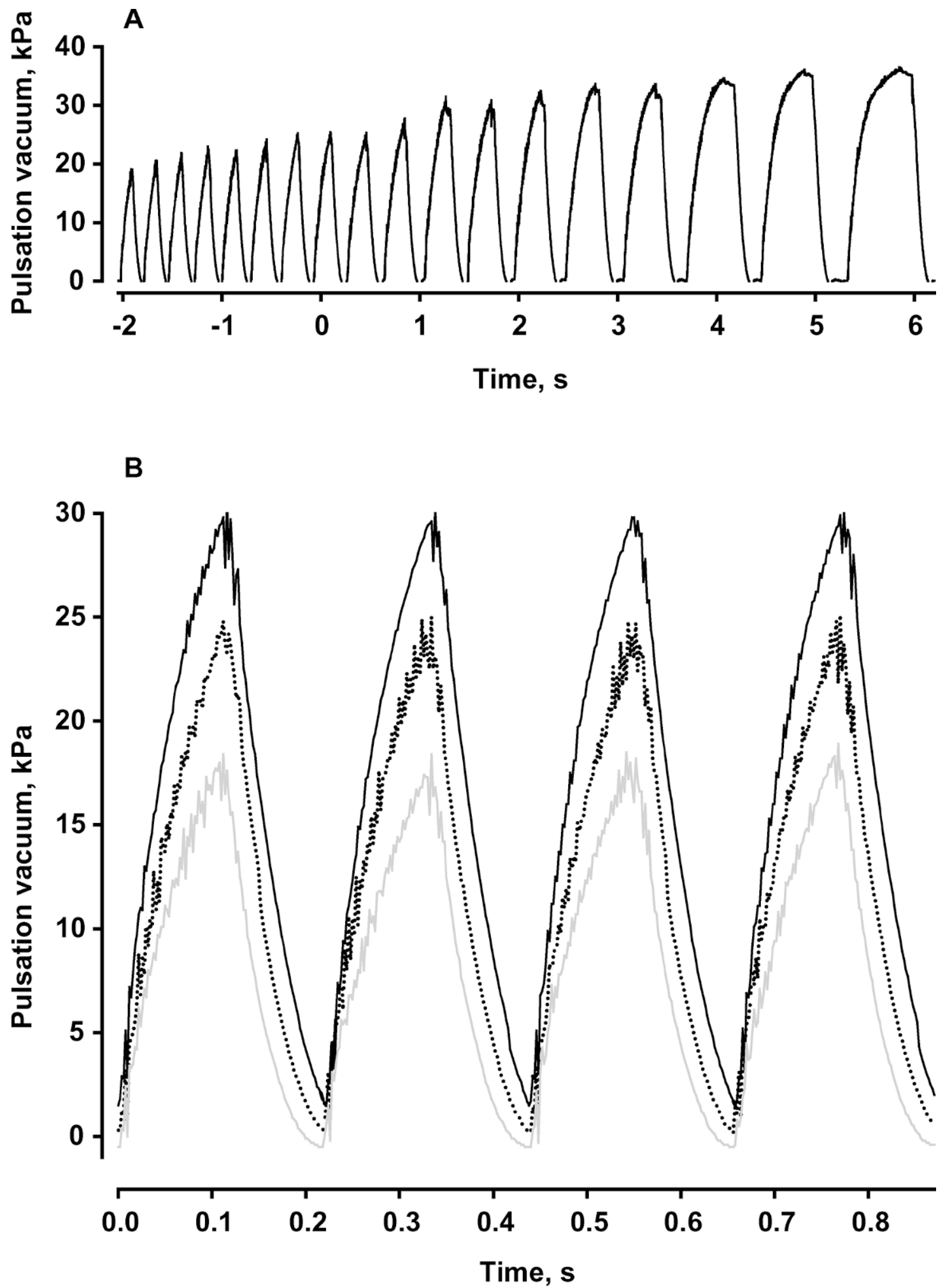

Figure 1. Pulsation chamber vacuum, A) changeover from vibration stimulation to milking pulsation; milking pulsation began at $\mathrm{t}=0$. B) pulsation vacuum curve during the course of vibration stimulation differing for 3 different vacuum settings: $30 \mathrm{kPa}$ (一) of maximum pulsation vacuum (MPV), $24 \mathrm{kPa}$ (- - -) of MPV, and $17 \mathrm{kPa}($-) of MPV. 
where $\mathrm{Y}_{\mathrm{ijk}}=\mathrm{OT}$ results $(\mathrm{ng} / \mathrm{L}), \mu=$ overall mean, $\mathrm{T}_{\mathrm{i}}=$ effect of treatment ( $\mathrm{i}=1$ to 4 ), $\mathrm{S}_{\mathrm{j}}=$ effect of time of sampling $(\mathrm{j}=-2$ to 7$), \operatorname{Cow}_{\mathrm{k}}\left(\mathrm{T}_{\mathrm{i}}\right)=$ repeated effect of cow ( $\mathrm{n}=1$ to 6 ) within treatment, and $\varepsilon_{\mathrm{ijk}}=$ residual error.

To analyze OT concentrations throughout milking, the area under the curve was calculated and analyzed using the model above omitting $\mathrm{S}_{\mathrm{j}}$ (time of sampling).

The model used to analyze experiments 2 and 3 was:

$$
\begin{gathered}
\mathrm{Y}_{\mathrm{ijklmno}}=\mu+\mathrm{T}_{\mathrm{i}}+\mathrm{U}_{\mathrm{j}}+\mathrm{T}_{\mathrm{i}} \\
\times \mathrm{U}_{\mathrm{j}}+\mathrm{L}_{\mathrm{k}}+\mathrm{D}_{\mathrm{l}}+\mathrm{Ti}_{\mathrm{m}}+\mathrm{S}_{\mathrm{n}}+\operatorname{Cow}_{\mathrm{o}}\left(\mathrm{T}_{\mathrm{i}}\right)+\varepsilon_{\mathrm{ijk} l m n o}
\end{gathered}
$$

where $\mathrm{Y}_{\mathrm{ijk} k \mathrm{mno}}=$ total milk yield $(\mathrm{kg})$, or stripping milk yield $(\mathrm{kg})$, or milk yield during vibration stimulation $(\mathrm{kg})$, or total milking time ( $\mathrm{min}$ ), or main milking time $(\mathrm{min})$, or peak flow rate $(\mathrm{min} / \mathrm{kg})$, or average flow rate (kg/min), $\mu=$ overall mean, $\mathrm{T}_{\mathrm{i}}=$ effect of treatment $[\mathrm{i}=$ 1 to 5 (experiment 2 ) or 1 to 2 (experiment 3 )], $\mathrm{U}_{\mathrm{j}}=$ effect of udder fill class $(\mathrm{j}=1$ to 5$), \mathrm{L}_{\mathrm{k}}=$ random effect of lactation number ( $k=1$ to 6$), D_{1}=$ random effect of day of milking ( $\mathrm{l}=$ date of milking $), \mathrm{Ti}_{\mathrm{m}}=$ random effect of time of milking ( $m=1$ to 2 , morning - evening), $\mathrm{S}_{\mathrm{n}}=$ random effect of stage of lactation ( $\mathrm{n}=$ days of lactation), $\operatorname{Cow}_{0}\left(T_{i}\right)=$ repeated effect of cow (o=1 to 43) within treatment, and $\varepsilon_{\mathrm{ijklmno}}=$ residual error.

Differences were localized with Student's $t$-test. The REG procedure in SAS was used to analyze the coefficients of correlation between udder fill and lag time of milk ejection.

\section{RESULTS}

\section{Experiment 1}

Oxytocin concentrations. Premilking OT concentrations were low and similar in all treatments (Figures 2 and 3). A significant increase in OT concentrations was observed within $30 \mathrm{~s}$ after the start of stimulation, irrespective of the applied treatment. In all treatments, OT concentrations were enhanced during the course of milking. Neither OT profiles during the course of stimulation and milking nor the area under the curve for OT concentration during milking were influenced by any applied prestimulation treatment, including the omission of prestimulation $(P=0.31)$. During milking without prestimulation (Figures $2 \mathrm{D}$ and $3 \mathrm{D}$ ), OT concentrations increased only after the start of milking. If prestimulation was applied (Figures 2A, B, C, and 3A, $\mathrm{B}$, and $\mathrm{C}$ ), OT concentrations increased after the start of stimulation and were already high at the start of milking.

Milk flow profiles. Examples of representative milk flow and OT profiles during 4 different treatments are
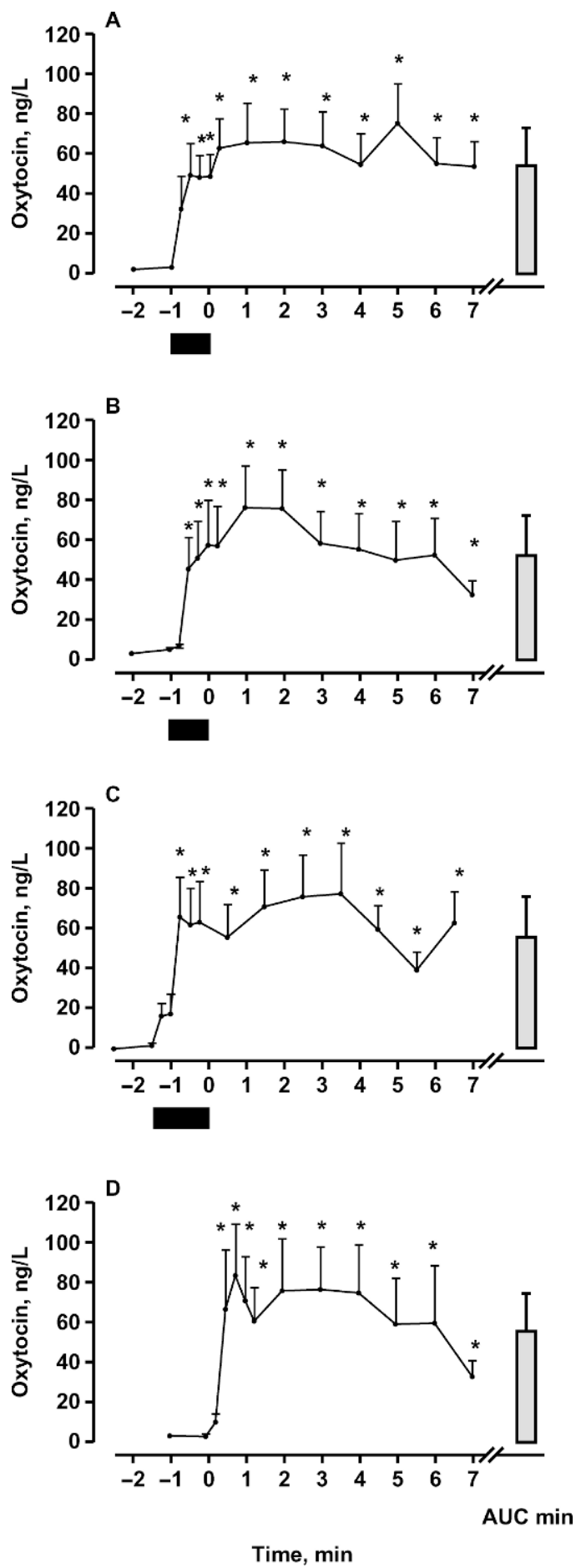

Figure 2. Means \pm SEM of oxytocin concentrations during the course of prestimulation and milking in 4 treatments. Milking pulsation began at $t=0$. Solid black bar indicates duration of prestimulation. A) $60 \mathrm{~s}$ vibration stimulation at a maximum pulsation vacuum (MPV) of $30 \mathrm{kPa}, \mathrm{B}) 60 \mathrm{~s}$ vibration stimulation with MPV of $17 \mathrm{kPa}$, C) $90 \mathrm{~s}$ of vibration stimulation with MPV of $17 \mathrm{kPa}$, and D) start of milking without previous prestimulation. AUC min = Area under the curve during main milking (0 to $7 \mathrm{~min})$. * Significant $(P<0.05)$ differences to basal concentration $1 \mathrm{~min}$ before the start of stimulation. 

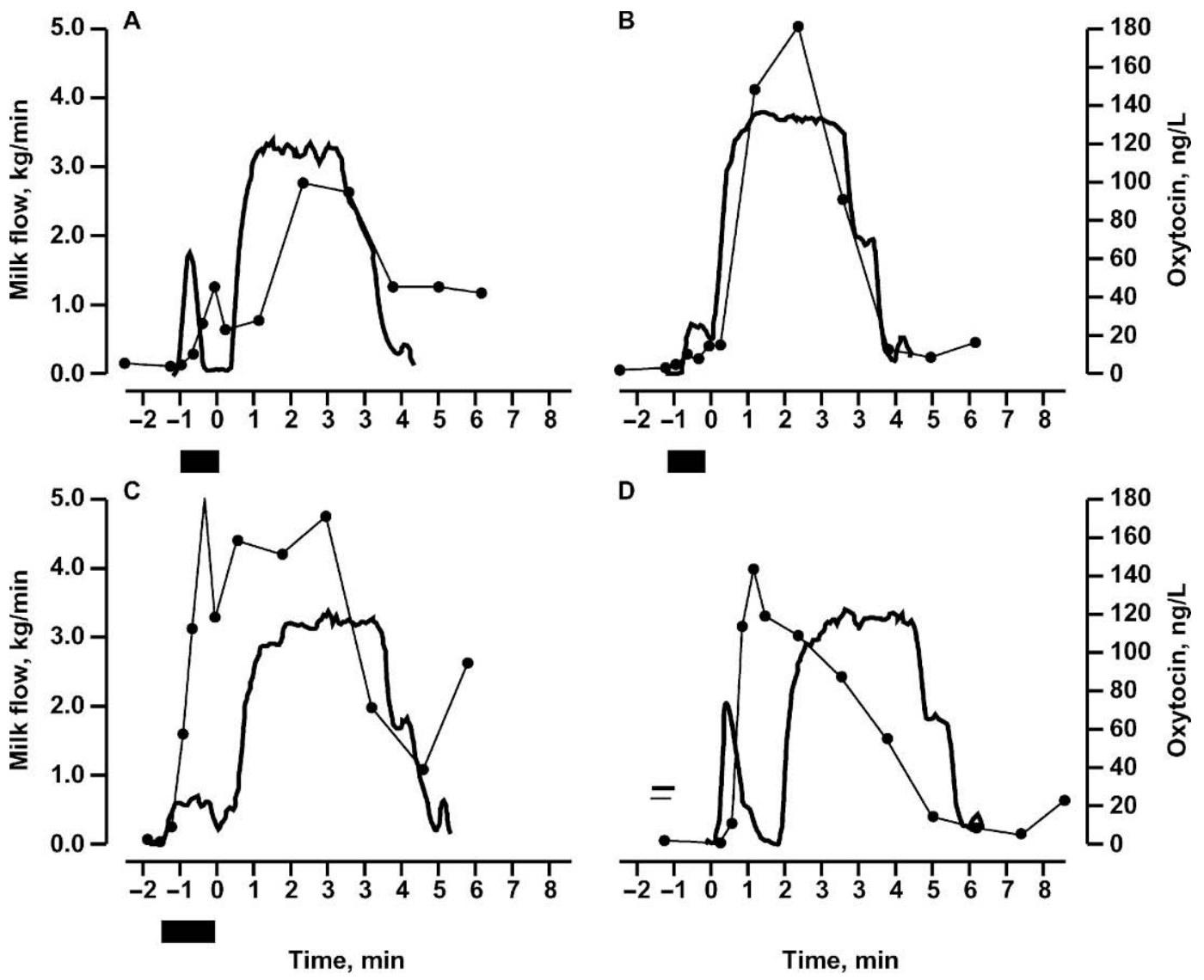

Figure 3. Oxytocin concentration (- - ) and milk flow (-) of one exemplary animal during the course of prestimulation and milking in 4 different treatments. Milking pulsation began at $\mathrm{t}=0$. Solid black bar indicates duration of prestimulation. A) $60-\mathrm{s}$ vibration stimulation with maximum pulsation vacuum (MPV) of $30 \mathrm{kPa}, \mathrm{B}) 60$-s vibration stimulation with MPV of $17 \mathrm{kPa}$, C) 90 -s of vibration stimulation with MPV of $17 \mathrm{kPa}$, and $\mathrm{D}$ ) start of milking without previous prestimulation.

presented in Figure 3. Even during prestimulation, milk flow was observed at an MPV of $30 \mathrm{kPa}$ (Figure $3 \mathrm{~A}$ ), whereas during prestimulation with a lower MPV (Figures 3B and C), only marginal milk flow was observed. During milking without prestimulation (Figure 3D), the milk flow increased immediately after the start of milking, however a transient reduction of milk flow was observed similar to that in Figure 3A.

\section{Experiment 2}

In Table 1, various milking characteristics are presented differing for the duration of prestimulation. Milk yield and stripping yield did not differ between treatments. Total milking time (including prestimulation and stripping) was shortest without prestimulation and longest when a 90 -s prestimulation was applied. Contrary, main milking time, that is, without the duration of prestimulation and without machine stripping was shortest with longest duration of prestimulation and vice versa. Peak flow rate (PFR) was highest at longest duration of prestimulation. Similarly, average flow rate (AFR) during main milking time was increased with prolonged duration of prestimulation.

Figure 4 illustrates effects of the degree of udder fill and the duration of prestimulation on milk yield, main milking time including the duration of prestimulation, PFR, and AFR. Mean udder fill of the individual cow was calculated separately for morning and evening milkings. The number of observations was $14,23,31$, and 18 for udder-fill classifications of 20 to 40,40 to 60,60 to 80 , and 80 to $100 \%$, respectively, i.e., among 86 milkings in 43 cows. However, it must be considered that the mean udder fill throughout the experimental period was used to classify the individual cow. Milk yield was not significantly influenced by prestimulation regardless of udder fullness. Main milking time, including the duration of prestimulation, was prolonged with 
Table 1. Milk yield, stripping yield, total machine-on time, main milking time, peak flow rate, and main milk flow rate at different duration of vibration stimulation at $24 \mathrm{kPa}$ pulsation vacuum.

\begin{tabular}{|c|c|c|c|c|c|c|}
\hline \multirow[b]{2}{*}{ Milking variable } & \multicolumn{5}{|c|}{ Prestimulation $^{1}(\mathrm{~s})$} & \multirow{2}{*}{$\begin{array}{l}\begin{array}{c}\text { Treatment } \\
\text { effect }\end{array} \\
P \leq\end{array}$} \\
\hline & $0(\mathrm{n}=258)$ & $20(\mathrm{n}=267)$ & $40(\mathrm{n}=259)$ & $60(\mathrm{n}=272)$ & $90(\mathrm{n}=254)$ & \\
\hline Total milk yield $(\mathrm{kg})$ & $13.56 \pm 0.23$ & $13.58 \pm 0.25$ & $13.49 \pm 0.25$ & $13.58 \pm 0.24$ & $13.10 \pm 0.25$ & 0.53 \\
\hline Stripping milk yield $(\mathrm{kg})$ & $0.22 \pm 0.02$ & $0.26 \pm 0.03$ & $0.21 \pm 0.02$ & $0.23 \pm 0.02$ & $0.26 \pm 0.02$ & 0.36 \\
\hline Total milking time (min) & $8.54 \pm 0.14^{\mathrm{b}}$ & $8.81 \pm 0.13^{\mathrm{ab}}$ & $8.79 \pm 0.14^{\mathrm{ab}}$ & $9.05 \pm 0.13^{\mathrm{a}}$ & $9.08 \pm 0.14^{\mathrm{a}}$ & 0.03 \\
\hline $\begin{array}{l}\text { Main machine milking time } \\
\text { without prestimulation (min) }\end{array}$ & $7.24 \pm 0.13^{\mathrm{a}}$ & $7.05 \pm 0.12^{\mathrm{ab}}$ & $6.86 \pm 0.13^{\mathrm{abc}}$ & $6.72 \pm 0.12^{\mathrm{bc}}$ & $6.38 \pm 0.13^{\mathrm{c}}$ & $<0.001$ \\
\hline Peak flow rate $(\mathrm{kg} / \mathrm{min})$ & $2.77 \pm 0.05^{\mathrm{c}}$ & $2.81 \pm 0.05^{\mathrm{bc}}$ & $2.85 \pm 0.05^{\mathrm{abc}}$ & $2.86 \pm 0.05^{\mathrm{ab}}$ & $2.91 \pm 0.05^{\mathrm{a}}$ & 0.001 \\
\hline Average flow rate $(\mathrm{kg} / \mathrm{min})$ & $1.81 \pm 0.03^{\mathrm{e}}$ & $1.86 \pm 0.03^{\mathrm{d}}$ & $1.91 \pm 0.03^{\mathrm{c}}$ & $2.00 \pm 0.03^{\mathrm{b}}$ & $2.02 \pm 0.03^{\mathrm{a}}$ & $<0.001$ \\
\hline
\end{tabular}

a,b,c,d,e Means with different superscripts within a row differ significantly $(P<0.05)$.

${ }^{1}$ Prestimulation $=0,20,40,60$, or $90 \mathrm{~s}$ of prestimulation by vibration stimulation with $24 \mathrm{kPa}$ of maximum pulsation vacuum (MPV).

increasing duration of prestimulation in udders that were at least $60 \%$ full. Peak flow rate and AFR did not differ with increasing stimulation in full udders, but PFR and AFR were both improved with increasing duration of prestimulation for udders that were not full (Figure 4).

Figure 5 illustrates the relationship between udder fill and lag time until the start of alveolar milk ejection.
This result is based on milkings without prestimulation. Additionally, lag time in milk flow profiles in further treatments were considered, when the start of the alveolar milk flow could be clearly identified by a bimodal milk flow pattern or by a prolonged period of milking pulsation in the absence of milk flow. The lag time was about 50 to $60 \mathrm{~s}$ in full udders and increased to $120 \mathrm{~s}$ with decreasing udder fill. Udder fill and lag
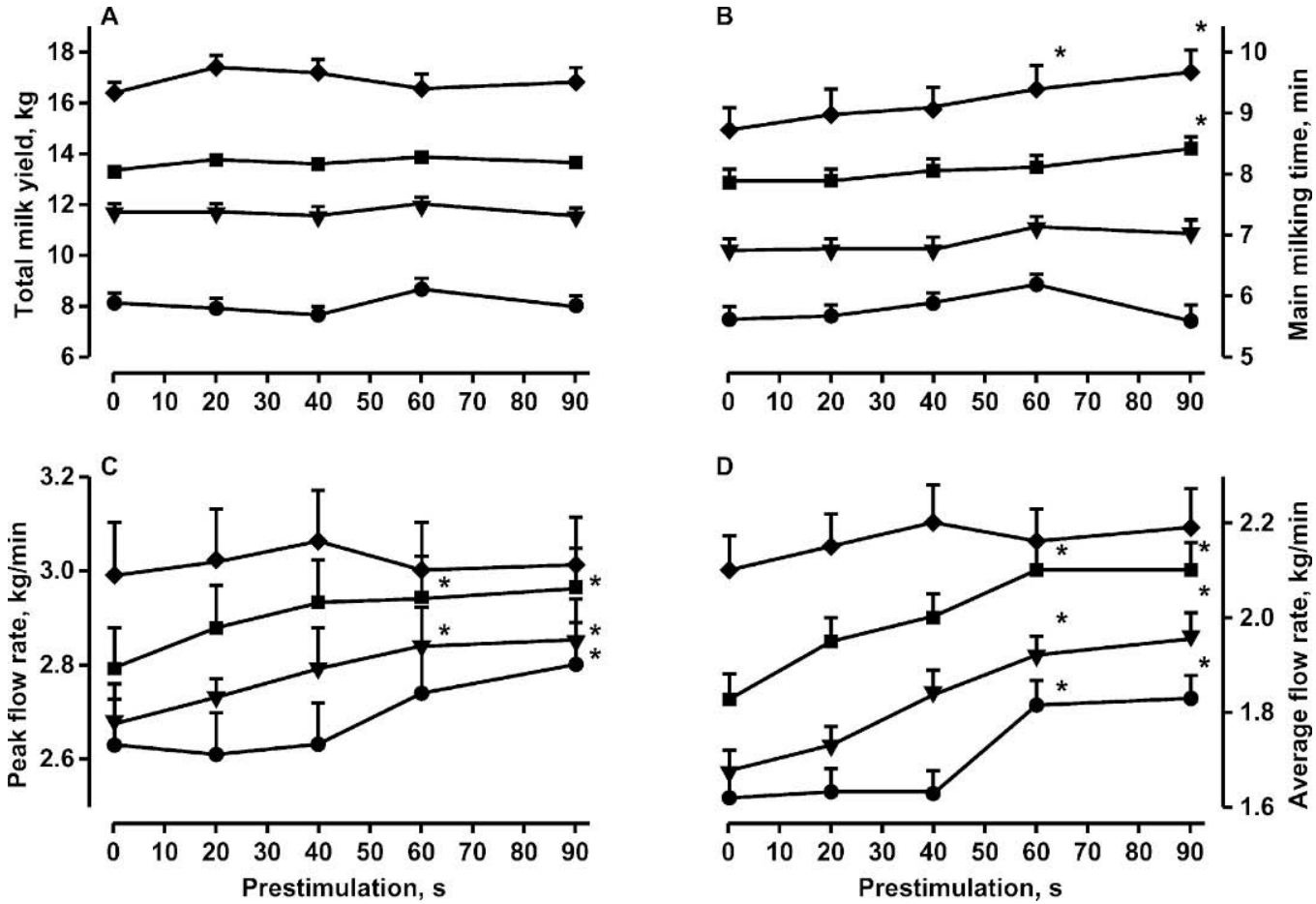

Figure 4. Means \pm SEM differing for the degree of udder fill and the duration of prestimulation. Symbols indicate classifications of udder fill: $\boldsymbol{\Theta}=20$ to $40, \boldsymbol{\Delta}=40$ to $60, \boldsymbol{\nabla}=60$ to 80 , and $\bullet=80$ to $100 \%$. A) total milk yield, B) main milking time including prestimulation duration, C) peak flow rate, and D) average flow rate during main milking. *Significant $(P<0.05)$ differences as compared with milking without prestimulation within one udder-fill classification. Significant differences among udder fill classifications were not indicated. 


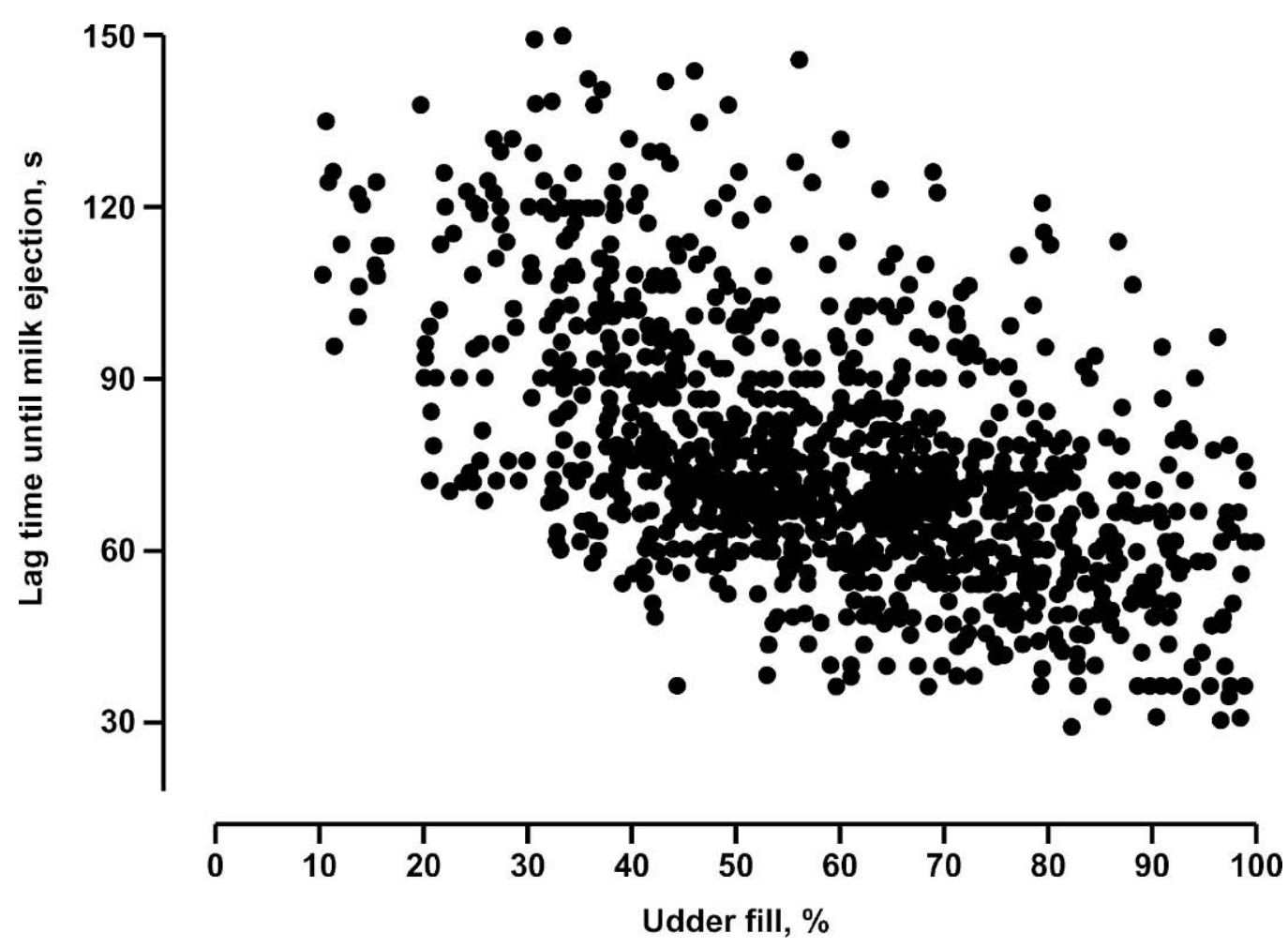

Figure 5. Relationship between udder fill and the lag time from start of teat stimulation until the start of alveolar milk ejection $(\mathrm{n}=$ 1191 milkings).

time until start of milk ejection was negatively correlated, with a Pearson's coefficient of $\mathrm{r}=-0.57(P<0.001)$ $[\mathrm{y}=117.27-0.69 \mathrm{x} ; \mathrm{x}=$ udder fill $(\%), \mathrm{y}=$ lag time from start of stimulation until milk ejection $(\mathrm{s})]$.

Representative milk flow profiles of 3 cows with different degrees of udder fill are shown in Figure 6. Time $\mathrm{t}=0 \mathrm{~s}$ indicates the start of milking pulsation. Each chart represents the milk flow profiles of 5 milkings differing for the applied duration of prestimulation (0, $20,40,60$, and $90 \mathrm{~s}$, respectively). Milking of a littlefilled udder (approximately 20\% udder fill) without prestimulation resulted in a lag in milk flow until $90 \mathrm{~s}$ after the start of milking (Figure 6A). Milk flow from the start of milking and a transient decrease of milk flow at 0.7 min was observed in a medium-filled udder (Figure 6B). Milking a full udder without prestimulation (Figure 6C) resulted in a prolonged increase phase, but no transient decrease in milk flow was observed. A fast increase and a steady plateau phase were observed after a specific duration of prestimulation at each level of udder fill. The optimum duration of prestimulation was 90,40 , and 20 s for little-, medium-, and well-filled udders, respectively.

\section{Experiment 3}

In Table 2, milking characteristics are presented for differing MPV. Except for the milk yield during vibra- tion pulsation, no significant differences in milking characteristics across MPV of 17 and $30 \mathrm{kPa}$ were observed.

\section{DISCUSSION}

In the present study milk flow and OT profiles were analyzed for several modes of tactile prestimulation by vibration stimulation. The basal OT level and the release of OT as result of tactile prestimulation were similar to those previously reported (Mayer et al., 1984; Bruckmaier and Blum, 1996; Bruckmaier and Hilger, 2001; Weiss et al., 2003). As in previous studies (Bruckmaier and Blum, 1996; Bruckmaier and Hilger, 2001), milking pulsation resulted in similar concentrations of OT compared with prestimulation by vibration stimulation. Oxytocin concentrations during the course of milking were not affected by the applied treatments. Therefore, the OT concentrations could not be enhanced by the application of prestimulation before milking compared with normal milking without prestimulation.

Consequently, and in agreement to several previous investigations (Sagi et al., 1980; Zinn et al., 1982; Karch et al., 1989; Rothenanger et al., 1995; Bruckmaier and Blum, 1996), milk yields were not affected by different prestimulation routines. The enhancing effect of prestimulation on PFR has been previously demonstrated 

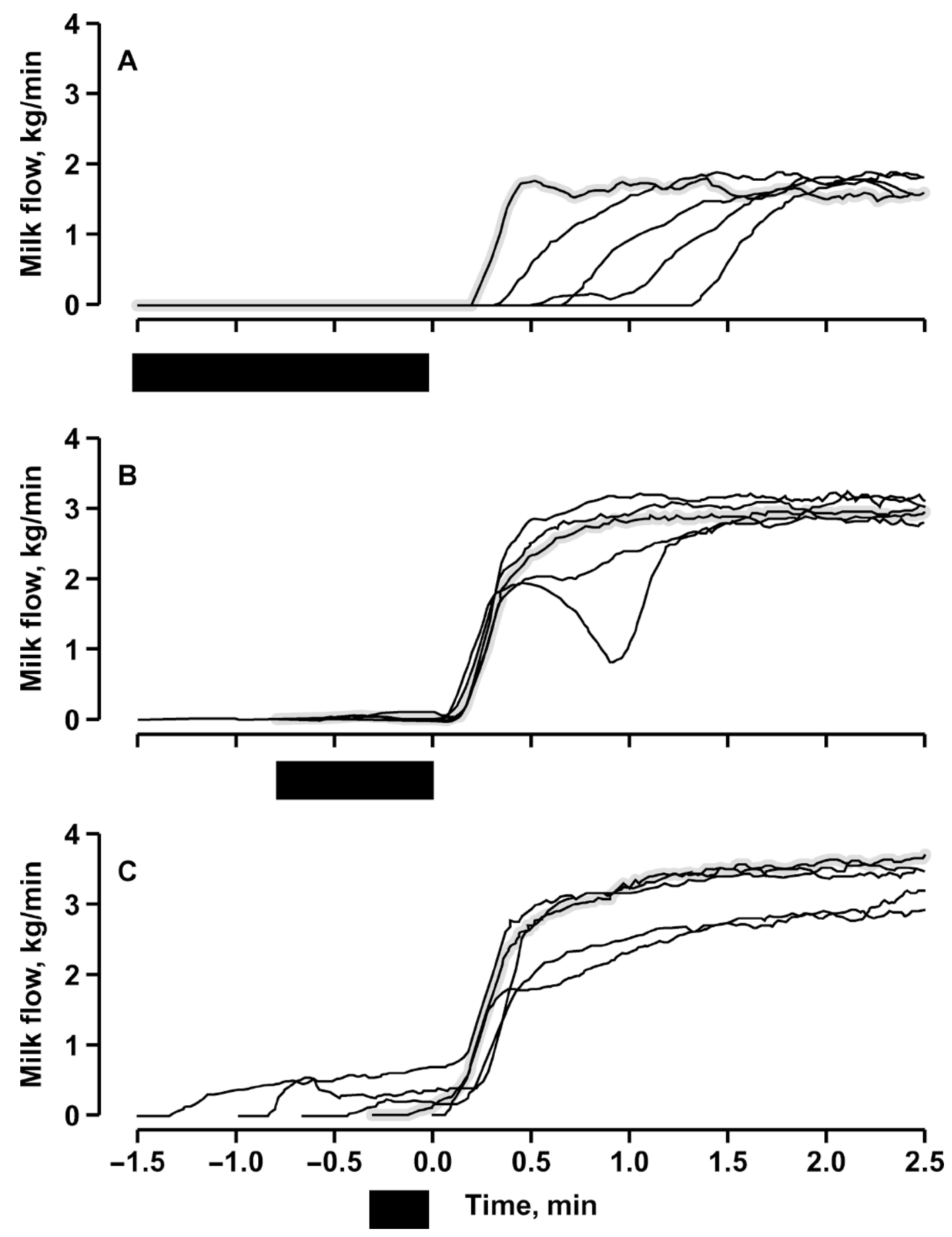

Figure 6. Milk flow profiles after varying prestimulation duration $(0,20,40,60$, and $90 \mathrm{~s}$ of vibration stimulation) in 3 different cows with A) low udder fill, B) moderate udder fill, C) high udder fill. Milking pulsation began at $\mathrm{t}=0$; each individual black line represents the milk flow profile until 2.5 min of milking, and the gray line represents the optimal milk flow profile. The solid black bar indicates optimal duration of prestimulation.

(Sagi et al., 1980; Zinn et al., 1982; Mayer et al., 1984; Bruckmaier and Blum, 1996). Interestingly, this effect was absent in udders that were more than $80 \%$ full.
The total machine-on time represents the time from start of prestimulation until the end of stripping. Therefore, the total machine-on time included the machine 
Table 2. Milk yield, stripping yield, total machine on time, main milking time, peak flow rate, and main milk flow rate at maximum pulsation vacuum of 17 and $30 \mathrm{kPa}$ during $60 \mathrm{~s}$ of vibration prestimulation.

\begin{tabular}{lccc}
\hline & \multicolumn{2}{c}{ Maximum pulsation vacuum $(\mathrm{kPa})$} & \\
\cline { 2 - 3 } & \multicolumn{1}{c}{$\begin{array}{c}17 \\
(\mathrm{n}=130)\end{array}$} & $\begin{array}{l}\text { Treatment } \\
\text { effect } \\
\text { Milking variable }\end{array}$ & $\begin{array}{c}30 \\
(\mathrm{n}=117)\end{array}$ \\
\hline Total milk yield (kg) & $12.68 \pm 0.36$ & $12.52 \pm 0.35$ & 0.83 \\
Stripping milk yield (kg) & $0.13 \pm 0.00$ & $0.21 \pm 0.03$ & 0.21 \\
Prestimulation milk yield (kg) & $0.25 \pm 0.03$ & $0.53 \pm 0.02$ & 0.02 \\
Total milking time (min) & $7.77 \pm 0.17$ & $8.01 \pm 0.18$ & 0.60 \\
Main machine milking time & & & \\
$\quad$ without prestimulation (min) & $6.29 \pm 0.16$ & $5.84 \pm 0.17$ & 0.32 \\
Peak flow rate (kg/min) & $2.97 \pm 0.07$ & $2.92 \pm 0.07$ & 0.75 \\
Average flow rate $(\mathrm{kg} / \mathrm{min})$ & $2.01 \pm 0.05$ & $2.12 \pm 0.05$ & 0.38 \\
\hline
\end{tabular}

stripping time and the time between the end of main milk flow and the start of machine stripping. The stripping yield was not influenced by the treatment. Therefore, special attention was paid to the main milking phase defined as milk flow from the start of milking pulsation until the milk flow dropped below a threshold of $0.3 \mathrm{~kg} / \mathrm{min}$.

An increased MPV during vibration stimulation resulted in removal of milk even during prestimulation. Maximum pulsation vacuum during vibration stimulation did not influence OT release. Maximum pulsation vacuum of 17 and $24 \mathrm{kPa}$ resulted in a vibration of the liner in its closed position. Only when an MPV of 30 $\mathrm{kPa}$ was applied did the liner start to open at peak pulsation vacuum. An MPV of $30 \mathrm{kPa}$ during vibration stimulation enabled a considerable milk flow even during the application of prestimulation. However, as milkability was not affected by an enhanced MPV, a partial removal of the cisternal milk obviously does not benefit the alveolar milk ejection, even in well-filled udders. An increased MPV doubled the milk yield during the vibration pulsation phase, but this milk represented only $4 \%$ of the total milk yield. These results are in agreement with previous by Karch et al. (1989).

The fact that OT release was not influenced by MPV confirms previous results that minimal mechanical impulses are sufficient to release OT and to start milk ejection (Weiss et al., 2003). Therefore, a further step toward an optimized prestimulation is to analyze the optimal duration of prestimulation in individual cows.

According to current and previous results, no cisternal milk was available when milking started without prestimulation at a low udder fill (Knight et al., 1994; Bruckmaier and Hilger, 2001). Therefore, the milk flow started after the start of the alveolar milk ejection at $90 \mathrm{~s}$. The start of alveolar milk ejection relative to the start of milking pulsation $(\mathrm{t}=0 \mathrm{~s})$ could be manipulated by the application of prestimulation. The start of milk flow was gradually shifted relative to the start of milk- ing by the application of prestimulation in little-filled udders. When a 90 -s prestimulation was applied, the milk flow started when milking pulsation started. Without prestimulation, teats were milked without milk flow until the alveolar milk ejection occurred. Therefore, the optimal prestimulation duration was $90 \mathrm{~s}$ in case of a little-filled udder. At moderate udder fill, cisternal milk was immediately available for milking (Bruckmaier and Blum, 1996) and the alveolar milk ejection started about $70 \mathrm{~s}$ after the start of prestimulation as indicated by the second rise of milk flow (Bruckmaier and Blum, 1996; Bruckmaier and Hilger, 2001). However, the amount of cisternal milk was not sufficient to bridge the gap until the start of alveolar milk ejection. In this case, the milk flow decreased when the cisternal milk was removed. In full udders, the amount of cisternal milk was further enhanced (Pfeilsticker et al., 1996) and the lag time until the start of the alveolar milk ejection was further reduced (Bruckmaier and Hilger, 2001). Optimal duration of prestimulation, i.e., the minimum duration necessary to receive immediate and continuous milk flow after the start of milking varied widely among cows. However, in discussing optimal duration of prestimulation according to the degree of udder fill, there are 2 effects to consider. An increasing udder fill reduces the lag time from start of teat stimulation until the start of alveolar milk ejection (Bruckmaier and Hilger, 2001). Furthermore, the amount of cisternal milk is higher with increased udder fill (Knight et al., 1994; Pfeilsticker et al., 1996). However, because the amount of cisternal milk and the individual milk flow rate is variable between cows (Bruckmaier et al., 1995; Rothenanger et al., 1995; Davis et al., 1998), the estimation of the buffer time of cisternal milk removal is inauspicious. On the other hand, there is a close relationship between lag time until the start of milk ejection and amount of udder fill. Therefore, the actual degree of udder fill provides important information to optimize the prestimulation duration. 
Prestimulation resulted, except for full udders, in increased AFR. However, increased AFR does not necessarily result in reduced time for the milking process, because the prestimulation duration is not considered in the current definition of AFR. The optimal duration of prestimulation represents the combination of a high AFR and a minimized milking time including the duration of prestimulation (machine on-time).

Compared with a fixed prestimulation duration of about 30 to $60 \mathrm{~s}$, an individual adjustment of prestimulation may provide 2 advantages. The milking stall capacity could be improved if milking of full udders was performed after reduced duration of prestimulation. A prolonged prestimulation mode at a low vacuum level just sufficient to prevent the fall-off of the milking cluster can reduce the duration of the full milking vacuum in less-filled udders. Because negative impacts of the milking vacuum load on teat tissue are well known (Hamann et al., 1993; Neijenhuis et al., 2001; Hillerton et al., 2002), an optimized prestimulation may improve teat condition.

However, when implementing these results in practice, premilking routines of individual farms have to be considered. The effective prestimulation duration should account for time spent cleaning teats and fore stripping, because even very weak mechanical impulses at dairy cows teats stimulate OT release (Weiss et al., 2003). If automatic milk meters measure milk yields regularly, the optimal prestimulation duration can be deduced considering the actual milk production and the milking interval.

\section{CONCLUSIONS}

Immediate and continuous milk flow after the start of milking results in a shorter duration of milking. A short prestimulation enhances milking stall capacity when milking full udders. If only a small amount of milk is present in the udder, prolonged prestimulation reduces the vacuum load on the teat. In dairy practice, it should be considered that any mechanical impulses to teats before milking, for example, teat cleaning or fore-stripping, cause a prestimulation and hence oxytocin release. Additional mechanical prestimulation by the milking machine should therefore be adjusted to farm-specific milking routines.

\section{ACKNOWLEDGMENTS}

This study was partially supported by WestfaliaSurge Oelde, Germany and by a grant of the Technical University Munich. We thank A. Knon and M. Schmölz for their excellent assistance during the milking experiments, and also C. Fochtmann and T. Dicker for their help during catheter experiments and oxytocin analyses.

\section{REFERENCES}

Bruckmaier, R. M., and J. W. Blum. 1996. Simultaneous recording of oxytocin release, milk ejection and milk flow during milking of dairy cows with and without prestimulation. J. Dairy Res. 63:201-208

Bruckmaier, R. M., and J. W. Blum. 1998. Oxytocin release and milk removal in ruminants. J. Dairy Sci. 81:939-949.

Bruckmaier, R. M., and M. Hilger. 2001. Milk ejection in dairy cows at different degrees of udder filling. J. Dairy Res. 68:369-376.

Bruckmaier, R. M., E. Rothenanger, and J. W. Blum. 1995. Milking characteristics in dairy cows of different breeds from different farms and during the course of lactation. J. Anim. Breed. Genet. 112:293-302.

Bruckmaier, R. M., D. Schams, and J. W. Blum. 1994. Continuously elevated concentrations of oxytocin during milking are necessary for complete milk removal in dairy cows. J. Dairy Res. 61:323-334.

Davis, S. R., V. C. Farr, P. J. Copeman, V. R. Carruthers, C. H. Knight, and K. Stelwagen. 1998. Partitioning of milk accumulation between cisternal and alveolar compartments of the bovine udder: Relationship to production loss during once daily milking. J. Dairy Res. 65:1-8.

Dzidic, A., D. Weiss, and R. M. Bruckmaier. 2004. Oxytocin release, milk ejection and milking characteristics in a single stall automatic milking system. Livest. Prod. Sci. 86:61-68.

Hamann, J., G. A. Mein, and S. Wetzel. 1993. Teat tissue-reactions to milking - Effects of vacuum level. J. Dairy Sci. 76:1040-1046.

Hillerton, J. E., J. W. Pankey, and P. Pankey. 2002. Effect of overmilking on teat condition. J. Dairy Res. 69:81-84.

Karch, G., H. Worstorff, and A. Prediger. 1988. Untersuchungen zum maschinellen Anrüsten mit dem Vibrationsverfahren unter besonderer Berücksichtigung des Zitzengummityps. Milchwissenschaft 43:18-21.

Karch, G., H. Worstorff, and A. Prediger. 1989. Untersuchungen zum maschinellen Anrüsten mit dem Vibrationsverfahren unter besonderer Berücksichtigung der Pulsierung. Milchwissenschaft 44:13-16.

Knight, C. H., D. Hirst, and R. J. Dewhurst. 1994. Milk accumulation and distribution in the bovine udder during the interval between milkings. J. Dairy Res. 61:167-177.

Lefcourt, A. M., and R. M. Akers. 1983. Is oxytocin really necessary for efficient milk removal in dairy cows? J. Dairy Sci. 66:2251-2259.

Mayer, H., D. Schams, H. Worstorff, and A. Prokopp. 1984. Secretion of oxytocin and milk removal as affected by milking cows with and without manual stimulation. J. Endocrinol. 103:355-361.

Mayer, H., H. Worstorff, D. Schams, and M. Klein. 1985. Secretion of oxytocin and milking characteristics in cows as affected by several modes of tactile teat stimulation. Milchwissenschaft 40:1-5.

Neijenhuis, F., G. H. Klungel, and H. Hogeveen. 2001. Recovery of cow teats after milking as determined by ultrasonographic scanning. J. Dairy Sci. 84:2599-2606.

Pfeilsticker, H. U., R. M. Bruckmaier, and J. W. Blum. 1996. Cisternal milk in the dairy cow during lactation and after preceding teat stimulation. J. Dairy Res. 63:509-515.

Rasmussen, M. D., E. S. Frimer, and D. M. Galton. 1992. The influence of pre-milking teat preparation and attachment delay on milkyield and milking. J. Dairy Sci. 75:2131-2141.

Rasmussen, M. D., E. S. Frimer, Z. Horvath, and N. E. Jensen. 1990. Comparison of a standardized and a variable milking routine. J. Dairy Sci. 73:3472-3480.

Rothenanger, E., R. M. Bruckmaier, and J. W. Blum. 1995. Association and dissociation of single quarter and total milk flow - Effects of milking with and without pre-stimulation. Milchwissenschaft 50:63-67. 
Sagi, R., R. C. Gorewit, W. G. Merrill, and D. B. Wilson. 1980. Premilking stimulation effects on milking performance and oxytocin and prolactin release in cows. J. Dairy Sci. 63:800-806.

SAS Institute. 1999. SAS/STAT Manual, release 8, Cary, NC.

Schams, D. 1983. Oxytocin determination by radioimmunoassay. III. Improvement to subpicogram sensitivity and application to blood levels in cyclic cattle. Acta Endocrinol. 103:180-183.

Weiss, D., A. Dzidic, and R. M. Bruckmaier. 2003. Effect of stimulation intensity on oxytocin release before, during and after machine milking. J. Dairy Res. 70:349-354.
Weiss, D., M. Hilger, H. H. D. Meyer, and R. M. Bruckmaier. 2002. Variable milking intervals and milk composition. Milchwissenschaft 57:246-250.

Worstorff, H., and R. Fischer. 1996. Verbesserungen in der Aufzeichnung und Auswertung von Milchflusskurven. Milchwissenschaft 51:663-666.

Zinn, S. A., R. C. Gorewit, and R. Sagi. 1982. Milking responses of cows given premilking stimulation at four lactational stages. J. Dairy Sci. 65:668-671. 